\title{
Discussion on the Construction of Teaching Center for Virtual Simulation Experiment in the Field of Oil and Gas Development
}

\author{
Heping Pu1 , Guili Zhang1, Zhaoxue Guo², Yongyou Wang² \\ ${ }^{1}$ Network and Information Center, Southwest Petroleum University, Chengdu, China \\ ${ }^{2}$ Petroleum Engineering School, Southwest Petroleum University, Chengdu, China \\ Email: puheping@swpu.edu,15995648@qq.com,guozx@swpu.edu.cn,wangyongyou@swpu.edu.cn
}

How to cite this paper: $\mathrm{Pu}, \mathrm{H}$. P., Zhang, G. L., Guo, Z. X., \& Wang, Y. Y. (2020). Discussion on the Construction of Teaching Center for Virtual Simulation Experiment in the Field of Oil and Gas Development. Creative Education, 11, 639-651. https://doi.org/10.4236/ce.2020.115048

Received: April 10, 2020

Accepted: May 5, 2020

Published: May 8, 2020

Copyright $\odot 2020$ by author(s) and Scientific Research Publishing Inc. This work is licensed under the Creative Commons Attribution-NonCommercial International License (CC BY-NC 4.0).

http://creativecommons.org/licenses/by-nc/4.0/

\begin{abstract}
The establishment of teaching center for the virtual simulation experiment in the field of oil and gas development can solve the lack in teaching experiment and skills training in the $t$ transmission oil drilling engineering area, and applied in the technology of computer graphics, human-computer interaction technology, virtual reality technology, modern occupation education theory and related theory of petroleum engineering. With the virtual simulation experiment, the petroleum engineering teaching can combine the field operation and skill practice together, thus exposing those experimental personnel to the true experience of the accidents but not bearing any danger or harm. This paper deriving from the perspective of the teaching resources and the teaching platform, expounds the construction of the national teaching center for virtual simulation experiment of oil and gas development.
\end{abstract}

\section{Keywords}

Petroleum and Gas Engineering, Oil and Gas Development, Virtual Simulation Experimental Teaching

\section{Introduction}

In order to comply with the development of the petroleum industry and the need of continuing education in oil fields, we have focused on the development of simulation systems for petroleum engineering and petroleum equipment, and have achieved a series of application results in completely independent intellectual property rights. In particular, simulators for oil production engineering, oil and gas storage and transportation, logging, and underground operations have met the experimental and practical skills training programs for petroleum courses (Reid 
et al., 2001). At the same time, the virtual simulation software system of experiment and training based on 3D serious game theory has been upgraded and developed like "simulation system on oil and gas exploitation safety accident" and "virtual training system on well-control". The advanced semi-physical simulation systems such as underbalanced drilling simulator and pressure-controlled drilling simulator, as well as virtual simulation system based on virtual reality and engineering simulation have been developed to meet the needs of fostering inter-disciplinary talents. A set of virtual simulation experiment teaching systems for oil and gas development are under constructed.

\section{Resources of Virtual Simulation Experiment Teaching System for Oil and Gas Development}

During years of the development process of virtual simulation experiment system, the leading team follows the principle of "strengthening" the foundation, broadens the profession, pays attention to quality education and ability training, reaches the talent market and enhances the adaptability of graduates", and organically combines the theory of oil and gas drilling, mining and transportation and virtual simulation technology to develop and produce various types of virtual simulation experiment systems and teaching resources. A three-major-type of virtual simulation systems (with different teaching levels) that integrate the basic teaching, comprehensive and innovative experiments, and the mutual promotion of classroom teaching and experiment teaching are preliminarily constructed. The three major types of virtual simulation systems include a series of simulation operation platform based on semi-physical simulation (Xing et al., 2016), virtual simulation operation platform based on three-dimensional serious game theory, simulation operation and development platform based on virtual reality and engineering reality, which can meet the needs of basic skills and hands-on ability training for relevant professionals in oil and gas engineering fields, assessment and safety education, and has accumulated rich experience in development of virtual simulation experiment teaching platform. The virtual simulation experiment teaching system and teaching resources that have been developed are shown in Figure 1.

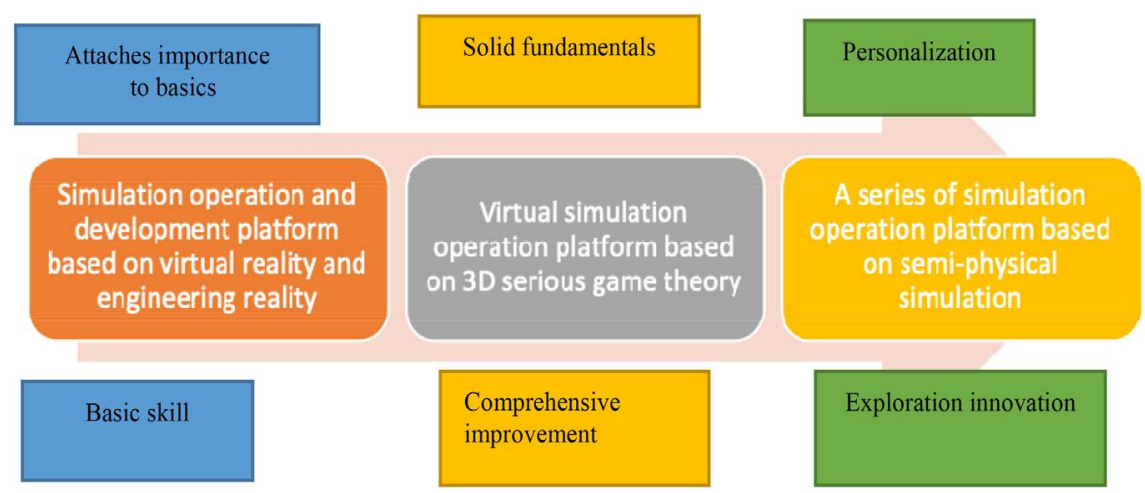

Figure 1. Virtual simulation experiment teaching system and distribution of teaching resources. 


\subsection{A Series of Simulation Operation Platform Based on Semi-Physical Simulation}

\subsubsection{Drilling Technology Simulation System}

Drilling technology simulation system includes simulation operating systems of drilling well-control, underbalanced drilling and pressure control drilling. Students observe the interaction of analog devices and display data on instrumentation, abnormal phenomena in virtual operating environments, and the working conditions of related equipment. And then they can comprehend much knowledge like: what is wellbore; the principle of formation fluid flow and the process of overflow; the principle of removing cutting debris in wellbore; the principle of conventional drilling, shut-in and well kill; the handling process of downhole accident; the principle of bottom hole pressure control for special drilling technology such as underbalanced drilling and pressure control drilling; ground special equipment and so on ( $\mathrm{Xu} \& \mathrm{Li}, 2007)$. The simulator of drilling well-control is shown in Figure 2(a) and Figure 2(b). Selecting a Template (Sub-Heading 2.1).

Through visual simulation experiments, students can form a perceptual understanding of evolution of characteristic parameters of multiphase flow in complex media under different working conditions such as underbalance, pressure control and gas drilling. Meanwhile, the established physical and mathematical models can be verified and corrected by measuring relevant parameters. The visual simulation experiment device is shown in Figure 3.

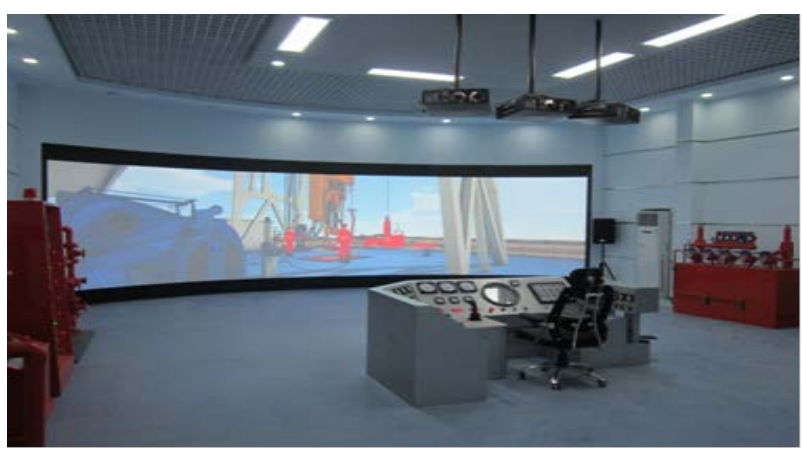

(a)

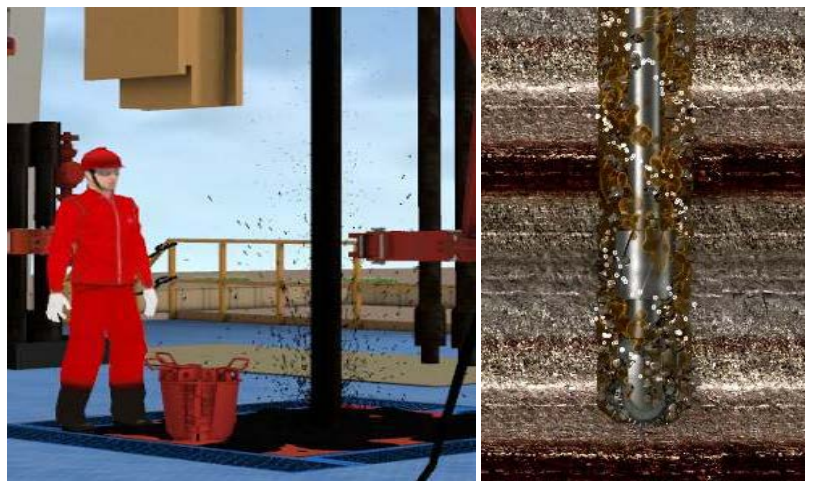

(b)

Figure 2. (a) Simulation operating system of drilling and well-control; (b) Real-time virtual process and component disassembly of drilling and well-control simulation system. 


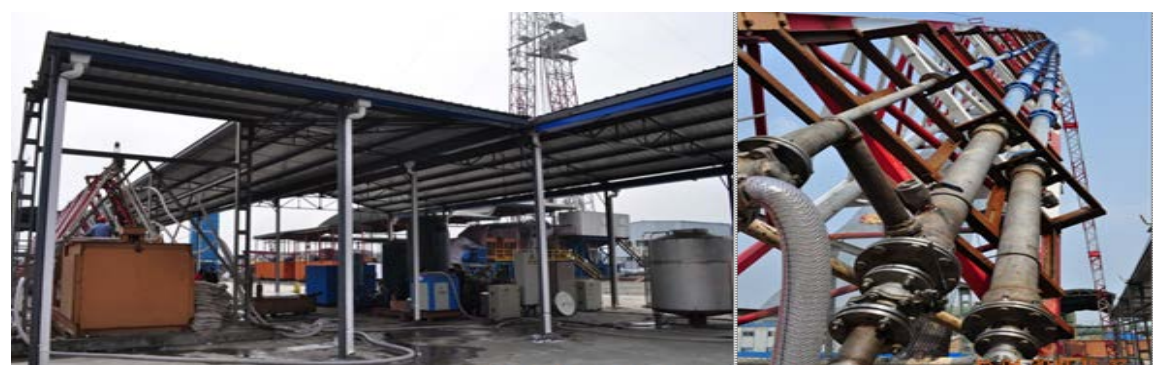

Figure 3. "Virtual and real combination" simulation experiment bench with large multiphase flow at any angle and 36 meters in height.

\subsubsection{Oil and Gas Exploitation Simulation System}

Students will master knowledge such as the multi-phase flow pattern of oil and gas wells, comparing with the accuracy of multi-phase flow calculation models, simulation and diagnosis of artificial lift methods (gas lift, electric submersible pumps, rod pumps, jet pumps, etc.), simulation of drainage and gas production processes and water injection projects by observing the interaction of analog devices and display data on instrumentation, abnormal phenomena in virtual operating environments, and the working conditions of related equipment. Some simulation devices are shown in Figure 4 and Figure 5.

\subsubsection{Simulation System of Oil \& Gas Gathering and Transportation} Students can comprehend the knowledge in the pipeline system of oil and gas gathering and transportation, the process of oil and gas gathering and transportation station, long distance pipeline of gas and pipeline, LNG receiving terminal and oil depot by observing the interaction of analog devices and display data on instrumentation, abnormal phenomena in virtual operating environments, and the working conditions of related equipment. Besides, students can get training on the layout of equipment of oil and gas gathering and transportation, internal structure and principle of equipment, operation and maintenance of equipment, operation skills of related technology and handling skills of common accident. The simulation system is shown in Figure 6 and Figure 7.

\subsection{Virtual Simulation Operation Platform Based on 3D Serious Game Theory}

\subsubsection{Interactive and Roaming Well-Control Virtual System}

At present, the single-machine version of virtual experiment teaching module of oil and gas drilling and well-control has been developed and put into use. The experimental and practical operation skill trainers can interactively set the conditions of formation and wellbore through the human-machine interface, and configure the operation equipment and engineering construction parameters according to the conditions of formation and wellbore by applying this system. Based on the data, the system generates the conditions of virtual formation wellbore, ground and downhole equipment. Visual 3D real time animation and real time data on virtual equipment are used to reflect the operation status of equipment, wellbore structure and formation environment, flow conditions of well fluids (Adaze et al., 2019) 


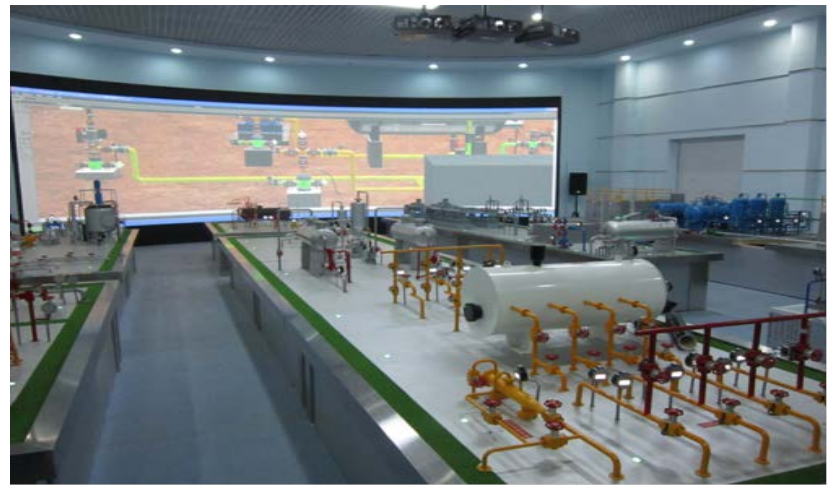

Figure 4. "Virtual and real combination" simulation laboratory of oil and gas exploitation.

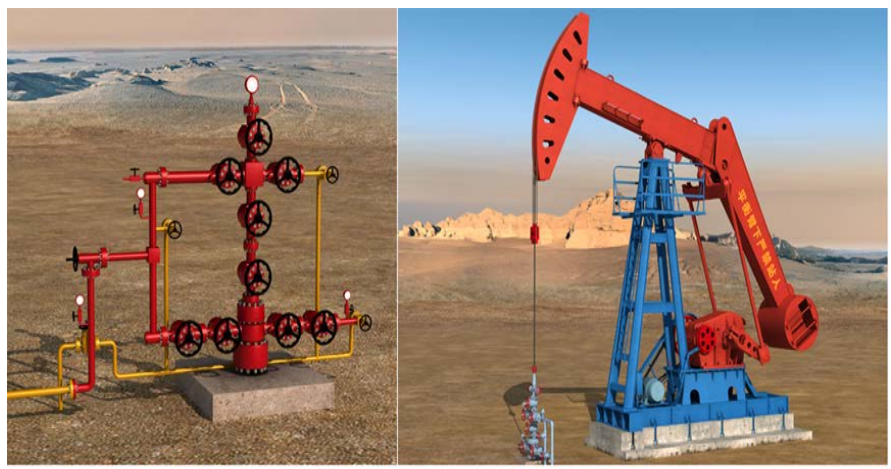

Figure 5. Partial display of "virtual and real combination" simulation of oil and gas exploitation.

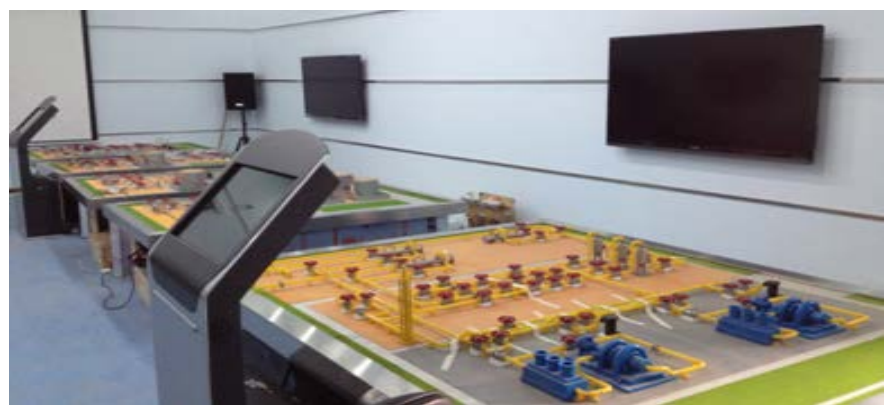

Figure 6. Layout of simulation system hardware of oil and gas gathering and transportation.

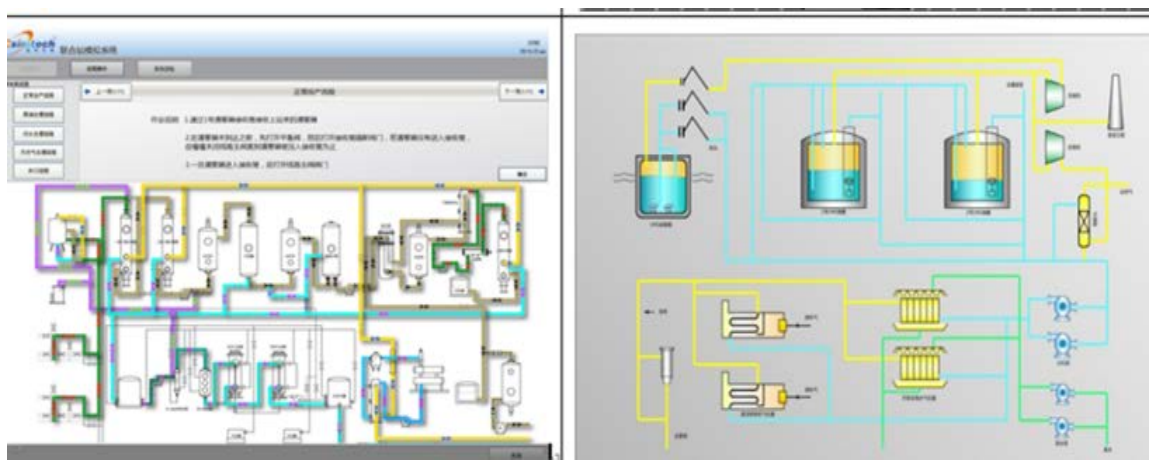

Figure 7. Software operation interface screenshot of simulation system oil and gas gathering and transportation. 
and formation fluids, dynamic display of theoretical or simulation data, simulation of abnormal conditions and phenomena. The animation and data can also track and evaluate the operation process and operation condition. The experimenter can play a certain job, roaming in the well site, operating the virtual equipment and observing the virtual instrumentation data. According to the knowledge, the experimenter can adjust the experimental parameters to complete the relevant experimental training projects which will achieve an organic combination of drilling well-control principles, field application and operation skills. The system possesses the teaching experiment and skill practice functions of the above-mentioned semi-physical simulation drilling and well-control simulator. The system is shown in Figure 8 \& Figure 9.

The majors, courses and experiments supported by the system are the same as the semi-physical simulation operating system.

\subsubsection{Simulation System of Oil and Gas Exploitation Safety}

In the process of oil and gas exploitation, accidents occur from time to time due to specially high temperature, high pressure, corrosive operating conditions, and easy diffusion of oil and gas as well as toxic gases such as hydrogen sulfide. Once improperly disposed, it is easy to cause huge economic losses and social hazards such as human and livestock casualties and environmental pollution. Such high-risk and complex engineering accidents cannot be inverted and analyzed by actual experiments. Therefore, reproduction of accident process, analysis of the causes and consequences, strategies of emergency treatment and plans of public escape can only be based on computational simulation technology (Bos et al., 2016). Southwest Petroleum University has used the scientific research results of oil and gas accident simulation analysis to teaching. The construction of the blowout out-of-control

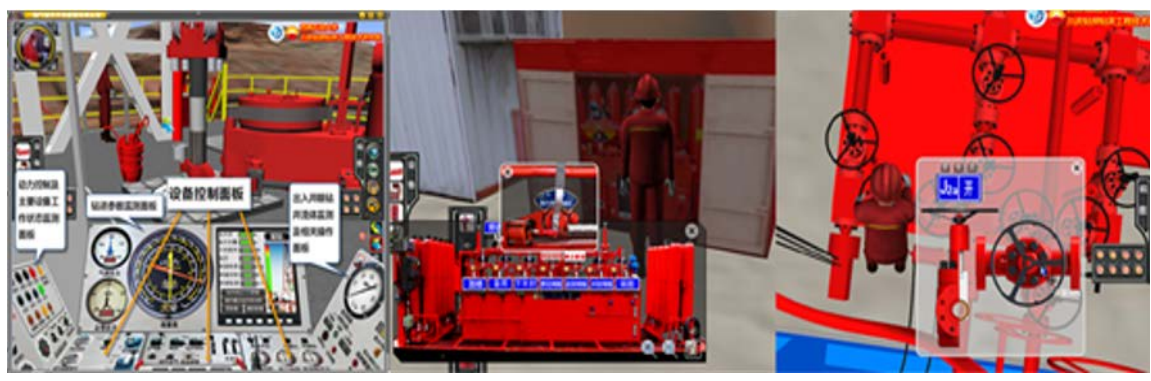

Figure 8. Interactive operation and parameter adjustment in $3 \mathrm{D}$ virtual simulation well field.
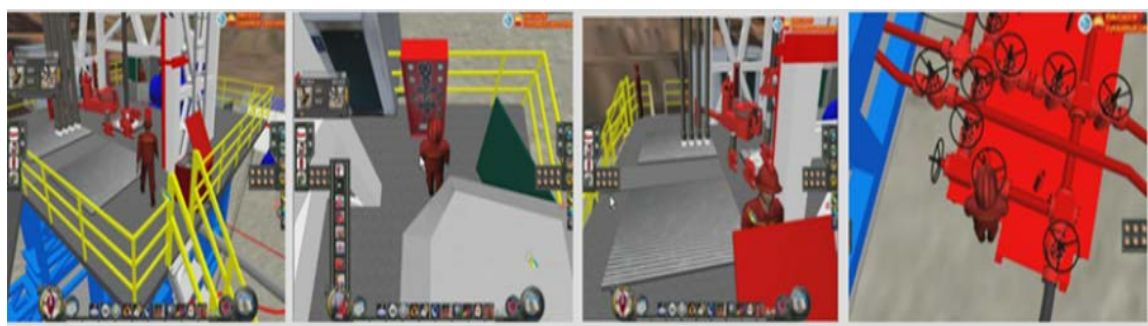

Figure 9. Interactive roaming in 3D virtual simulation wellsite. 
simulation analysis platform has been completed. It can be used as oil and gas exploration risk identification and safety education for oil and gas engineering and other related majors, and can also be used as a public resource to popularize oil and gas exploration risks and emergency escape knowledge (Freitas et al., 2014). Typical accident simulations are shown in Figures 10-12.

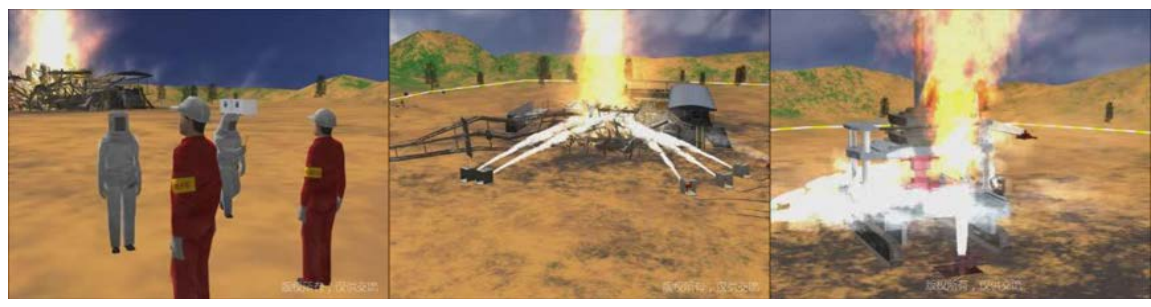

Figure 10. Virtual simulation experiment teaching system of blowout emergency exercise.

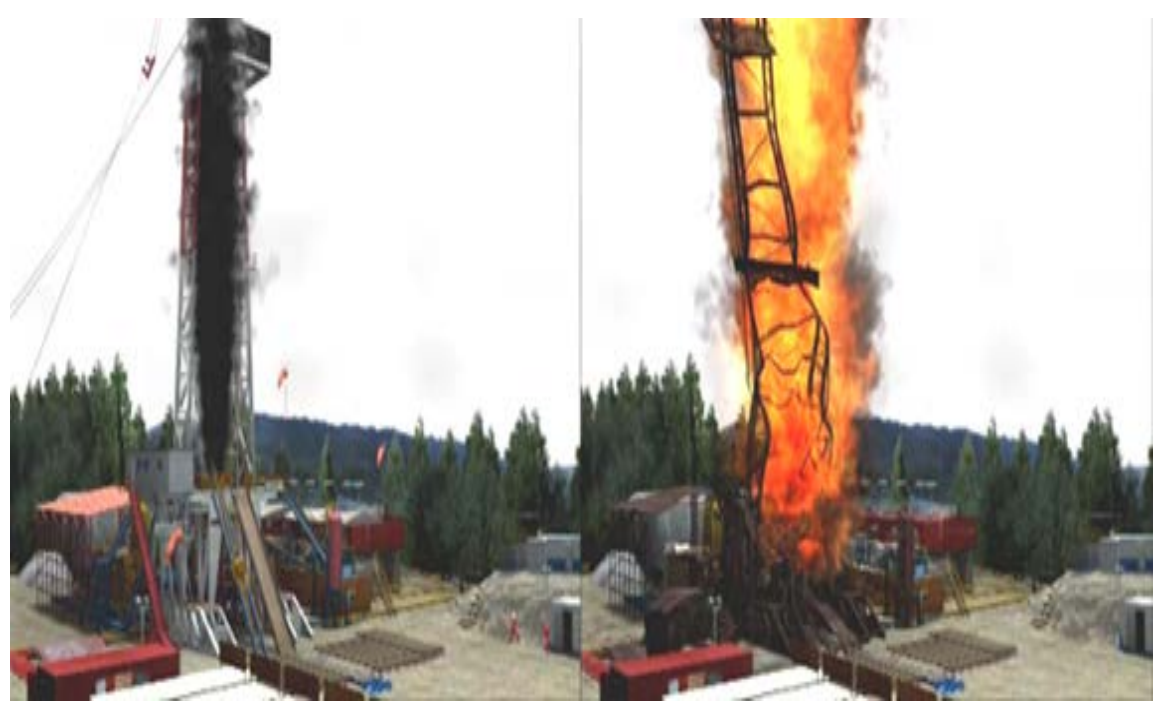

Figure 11. Virtual simulation inversion of blowout cause, process.

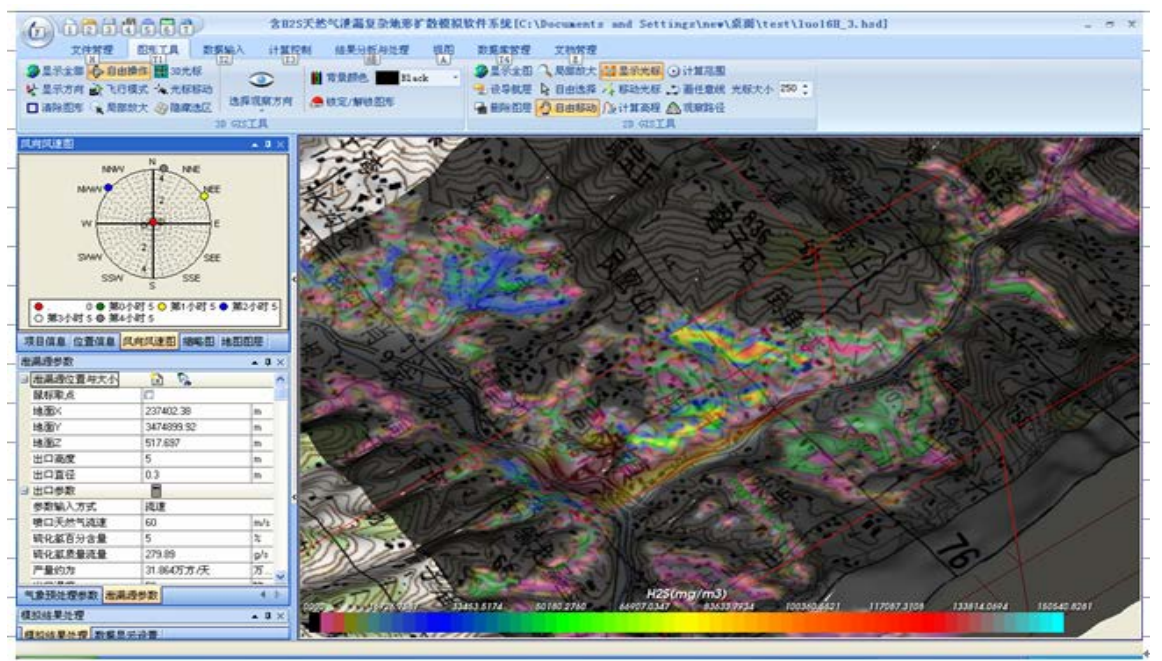

Figure 12. "Virtual and real combination" simulation and analysis system of complex terrain diffusion of toxic gas in blowout out-of-control. 
The rational use, continuous construction and sharing of these virtual simulation experiment teaching resources can meet the experiment teaching needs of oil and gas engineering related disciplines. What is more, it overcomes many disadvantages such as high cost, high consumption of resources (including energy and experimental raw materials) and serious environmental pollution.

\subsection{Simulation Operation and Development Platform Based on Virtual Reality and Engineering Reality}

\subsubsection{Design of Drilling Engineering and Analysis Virtual Reality System}

In addition to the actual drilling projects in the oilfield, the platform resources can also be used for the comprehensive application and innovation for students majoring in oil and gas engineering. It can provide a comprehensive experimental platform for multidisciplinary collaborative design of wellbore in geology and reservoir environment for students in drilling engineering, reservoir engineering and petroleum geology. It can be a comprehensive experimental platform for students engaged in reservoir, drilling and wellbore measurement to cooperate, monitor drilling processes, control drill bits to avoid geological and engineering risks and accurately enter oil and gas reservoirs. It can also provide a comprehensive experimental platform for people who work in the fields like drilling, oil production, mechanical equipment design and manufacturing to design drilling and mining equipment, downhole tools, and analyze the working conditions of underground tools (Lee et al., 2017).

Typical virtual simulation experiments are shown in Figure 13 and Figure 14.
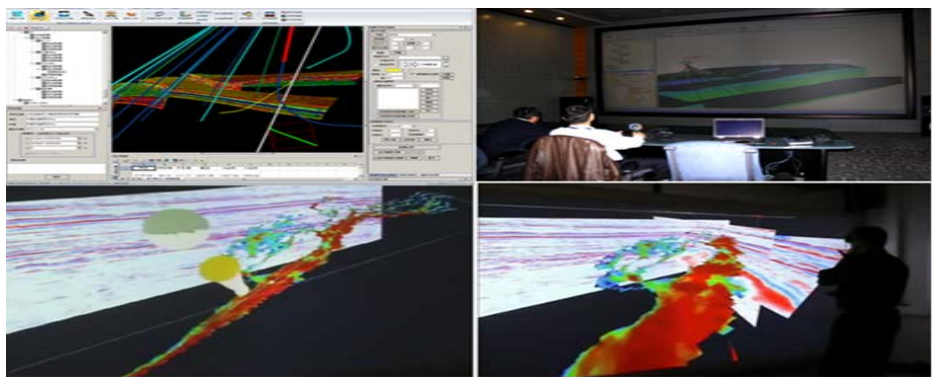

Figure 13. Multi-disciplinary experiment platform for well trajectory design and evaluation in immersive virtual reality environment.

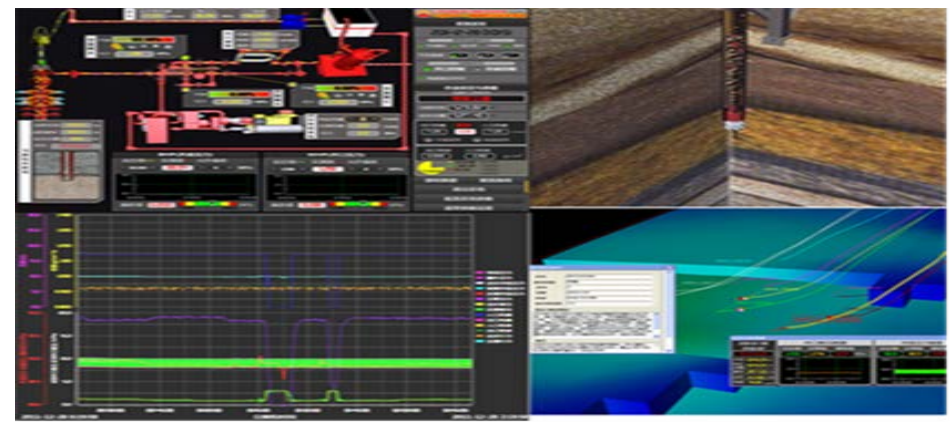

Figure 14. Multi-disciplinary experiment platform for drilling monitoring and trajectory control in drilling engineering. 


\subsubsection{Virtual Reality System of Marine Oil and Gas Exploitation}

In order to make up for the gaps in professional experiments and practices related to offshore oil and gas exploitation, teaching and research personnel in relevant fields have established a virtual reality simulation platform for marine oil and gas exploitation by taking advantage of virtual reality software and hardware platforms and advanced engineering simulation software, digital modeling software systems, and self-developed interactive virtual reality rendering and roaming and control software modules. It can simulate the working environment, working equipment, and process of marine oil and gas exploitation. The system is the most economical, safe, flexible and comprehensive experiment and training method for marine drilling, mining, and transportation. It has the functions of roaming in the virtual marine working condition, interactively disassemble or combine operation equipment and conduct some process stimulations (Mehmet \& Akbel, 2011). Typical examples are shown in Figures 15-17.

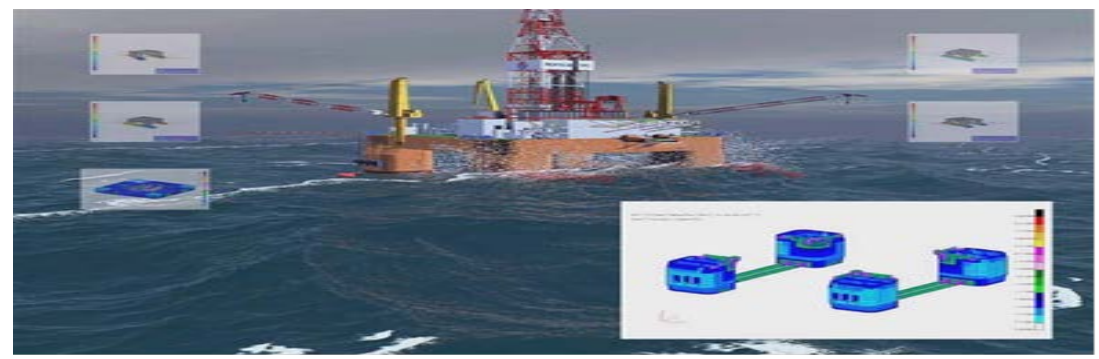

Figure 15. "Virtual and real combination" simulation experiment teaching module of marine drilling platform.

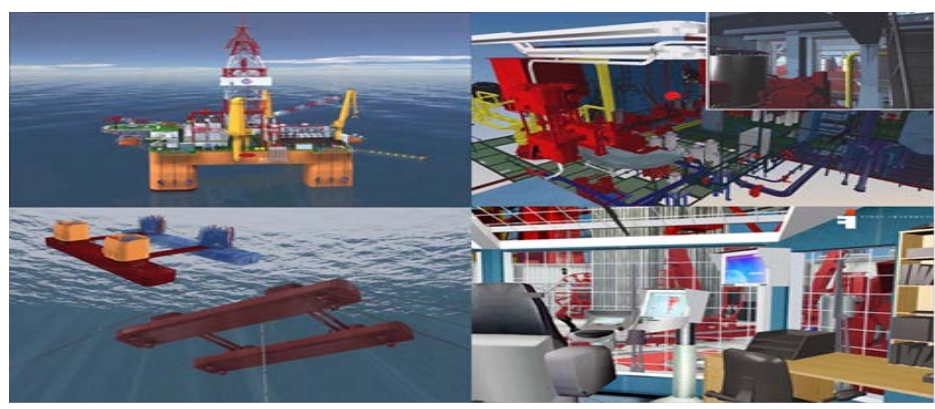

Figure 16. Disassembly experiment teaching module of marine oil and gas drilling virtual platform.

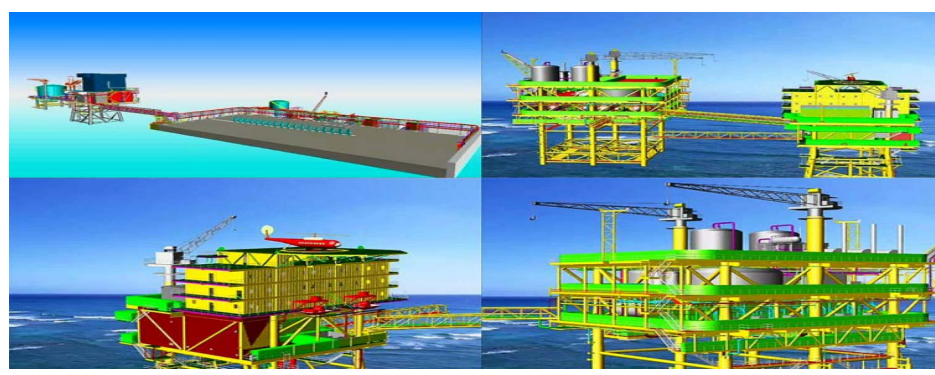

Figure 17. Experiment teaching module of marine oil and gas's exploitation and transportation and virtual environment and equipment. 


\subsubsection{Virtual Reality System of Underground Engineering and Wellbore Operation}

Drilling and mining projects are invisible underground and wellbore engineering, involving the interaction of formations, downhole tools, rocks, fluids, etc. In the teaching practice, it is necessary to visually display the technological principles, engineering phenomena and theoretical laws of the operations in the formation. The physical experimental devices cannot reach these goals from the simulation conditions and scale. Therefore, an underground virtual simulation teaching system for underground engineering and tools was established, which provided experiment teaching support for drilling and other related courses (Yu et al., 2010). The virtual reality dynamic simulation of formation and wellbore operations is shown in Figure 18.

\section{Teaching Platform for Virtual Simulation Experiment of Oil and Gas Exploitation}

According to the engineering theory, process features and production system in the field of oil and gas development, combined with the training requirements of oil and gas engineering and other related majors, the virtual simulation experiment teaching platform for oil and gas development is designed (Zhang et al., 2017). The specific functions of the teaching platform are as follows:

\subsection{The Three Major Platforms Undertake Different Experiment Teaching and Practical Tasks}

"A series of simulation operation platforms based on semi-physical simulation" mainly undertakes simulation training of drilling, exploitation, gathering, and transportation. It matches with related courses and belongs to basic teaching, focusing on cultivating students' mastery of basic theories and skills. "Virtual simulation operation platform based on the three-dimensional serious game theory" belongs to the comprehensive improvement platform, mainly based on case teaching, conducting interactive and roaming virtual training of well-control and mining accidents (including emergency plan) in typical accidents encountered in oil and gas drilling, mining and transportation. This platform focuses on training students'

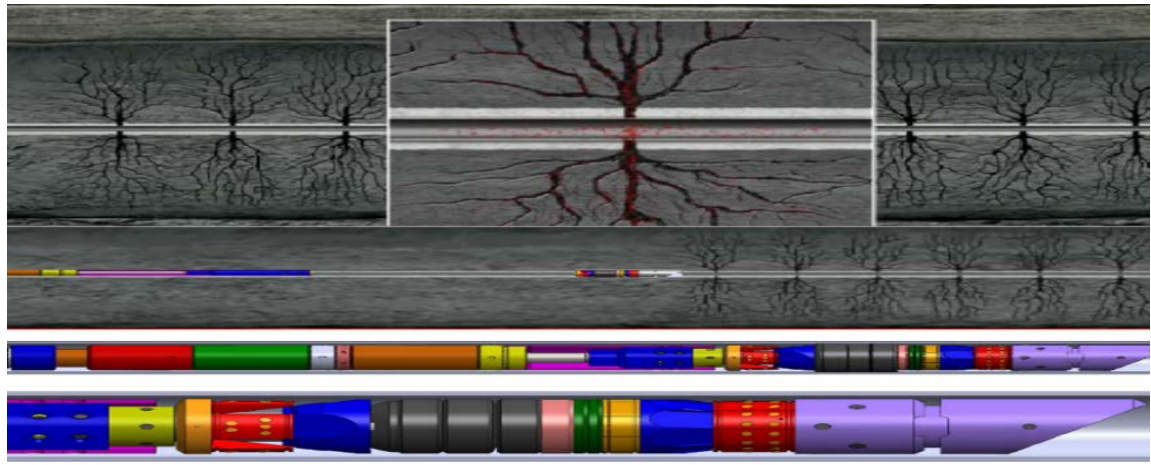

Figure 18. Virtual simulation experiment teaching system of formation and wellbore operation. 
operational ability and security awareness. "Simulation operation and development platform based on virtual reality and engineering reality" is a comprehensive training platform for students' abilities of practice, operation, exploration, and innovation. The platform is quite practical and the teaching content is closely integrated with the actual production of oil fields. At the same time, students are also allowed to use the platform to conduct personalized innovative experiments and design studies. The platform is mainly responsible for drilling engineering design and analysis of virtual reality teaching training, such as the marine oil and gas exploitation process, underground engineering and wellbore operations. The rational use of these three virtual or simulated experiment teaching platforms can effectively compensate for the shortcomings of conventional experiment teaching so as to achieve the organic unity of theoretical teaching and experimental practice teaching.

\subsection{Achieving a Combination of Macroscopic and Microscopic Simulation}

For oil and gas engineering, "macro simulation" is mainly a virtual simulation of the process of drilling engineering which is high-risk (high H2S gas field), high risk and high cost (shown in Figure 2 and Figure 3); virtual simulation of the process gathering and transportation (shown from Figures 4-7); virtual simulation of the process of drilling, mining and transportation in marine conditions (shown from Figures 15-17). The simulation system based on semi-physical, the virtual well-control system based on three-dimensional serious game theory, the virtual reality platform of marine oil and gas development, the virtual reality platform of formation and wellbore operation reflect the principle of macroscopic simulation. The function of its teaching platform is shown from Figures 2-18.

\subsection{Simulating High-Risk Conditions and Experiments Hard to Repeat}

As shown in Figure 3, Figures 10-12 and Figure 15, the series of simulation platforms that have been developed can reproduce underground, wellbore, toxic and harmful environments that people cannot access. Moreover, they can reproduce untestable and non-repeatable catastrophic accidents such as blowouts as well as repeatedly simulate irreversible downhole accidents. These platforms provide an effective means for the experiment teaching of drilling, mining, and transportation involved in the oil and gas development process.

\subsection{Manual Design of Experimental Parameters Can Be Carried Out to Simulate Training of Experimental Projects under Different Working Conditions}

As shown in Figure 13 and Figure 14, a variety of experimental parameters can be changed on all virtual simulation platforms, such as formation parameters, working fluid parameters, wellbore parameters, and equipment parameters to carry out simulation experiments under different working conditions and process 
conditions. It is also possible to manually configure, connect, adjust, and use virtual laboratory equipment. For example, in the virtual simulation experiment of well-control, students can independently select drilling and well-control equipment such as the Bop combination type and throttle manifold type according to the simulated formation conditions and wellbore conditions to complete typical shut-in and killing experiments.

\subsection{Not Only for Virtual Simulation Equipment and Environment, But Also Human-Machine Interaction}

As shown in Figure 2, Figures 7-9 and Figure 12, the experimenter can arbitrarily operate the physical simulation device and the virtual device in the virtual simulation system. The simulation device will respond to and analyze the correct operation and error operation from the experimenter and its consequences. This is not allowed in field devices. Experimenters can interactively roam and "arrive" anywhere in the virtual conditions of oil and gas engineering operations.

\subsection{Collecting \& Analyzing Experimental Results and Assessing Scores}

As shown from Figure 8 to Figure 9, Figure 13 and Figure 14, all the simulation experiment teaching systems can have a statistical analysis of the experimenter operation and provide judgment and operation reference for experimenters. For resources with micro or engineering numerical simulations, the calculation results can directly reflect the success or accuracy of the experiment, and can automatically assess the experimental grades.

\section{Summary}

After years of persistence and unremitting efforts, the Center has taken advantage of the human resources and technology in universities, and has paid attention to cooperation and exchanges with oilfield sites, and has gradually embarked on a path integrating production, education, and research. It has researched and developed oil engineering operation simulation systems for drilling, well-control, logging, oil and gas exploitation, pressure operation, underground operation, oil, and gas gathering and transportation, fracturing acidification, drilling rig installation, etc. The product line covers a complete field of application sites in the oil and gas industries. So far, the series simulation experiment training system of oil and gas development has been successfully applied to major domestic oil fields. We will combine the construction of the Center and adhere to the principle of "prominent professional characteristics of disciplines, focus on comprehensive quality training, and promote the growth of innovation consciousness", and follow the principle of combining virtual and real. What is more, we will plan, integrate effectively and improve existing experiment teaching resources, and ensure that all construction tasks of the virtual simulation experiment teaching center of oil and gas development go smoothly and achieve greater success. 


\section{Conflicts of Interest}

The authors declare no conflicts of interest regarding the publication of this paper.

\section{References}

Adaze, E., Al-Sarkhi, A., Badr, H. M., \& Elsaadawy, E. (2019). Current Status of CFD Modeling of Liquid Loading Phenomena in Gas Wells: A Literature Review. Journal of Petroleum Exploration and Production Technology, 9, 1397-1411. https://doi.org/10.1007/s13202-018-0534-4

Bos, P. J. et al. (2016). Simple Method to Reduce Accommodation Fatigue in Virtual Reality and Augmented Reality Displays. SID Symposium Digest of Technical Papers, 47, 354-357. https://doi.org/10.1002/sdtp.10678

Freitas, V. G. G., Mol, A. C. A., \& Shirru, R. (2014).Virtual Reality for Operational Procedure in Radioactive Waste Deposits. Progress in Nuclear Energy, 71, 225-231. https://doi.org/10.1016/j.pnucene.2013.11.003

Lee, Y. H. et al. (2017). Switchable Lens Based on Cycloidal Diffractive Waveplate for AR and VR Applications. SID Symposium Digest of Technical Papers, 48, 1061-1064. https://doi.org/10.1002/sdtp.11822

Mehmet, A., \& Akbel, A. (2011). Process Optimization with Simulation Modelling in a Manufacturing System. Research Journal of Applied Sciences, Engineering and Technology, 3, 318-329.

Reid, R. D., Reid, B., \& Sykes, W. N. (2001). Safety Training in Virtual Reality. In ASSE Professional Development Conference and Exposition (pp. 59-63). Anaheim, California: American Society of Safety Engineers.

Xing, Y. Y., Huang, H. B., \& Yang, X. M. (2016). 3D Digital Virtual Simulation Application System for Technical Management of Nuclear Power Station Equipment. In Y. Xu (Ed.), Nuclear Power Plants: Innovative Technologies for Instrumentation and Control Systems (Vol. 400, pp. 1-7). LNEE. Singapore: Springer. https://doi.org/10.1007/978-981-10-3361-2_1

Xu, Y. Q., \& Li, R. F. (2007). The Studies of the Construction of Digital Laboratory Based on Matlab and Java Applet. Microcomputer Information (Measurement and Control Automation, 113, 259-260.

Yu, T., Zhang, H., \& Li, M. (2010). A Mechanistic Model for Gas/Liquid Flow in Upward Vertical Annuli. In Proceedings-SPE Annual Technical Conference and Exhibition (pp. 35-30). New Orleans, Louisiana: Society of Petroleum Engineers. https://doi.org/10.2118/124181-PA

Zhang, G. L., Sun, Y., Li, P. X., \& Du, K. (2017). Research on Application Model of Big Data Technology in the A1A2 System. In 2017 IEEE 2nd International Conference on Big Data Analysis (ICBDA) (pp. 494-498). Piscataway: IEEE. https://doi.org/10.1109/ICBDA.2017.8078870 